\section{Task Force's Prevention Advice Proves Hard to Swallow}

The current chair of the U.S. Preventive Services Task Force defends the panel's controversial decisions on issues such as cancer screening

VIRGINIA MOYER, A PEDIATRICIAN WITH A keen interest in health screening, remembers what it was like to be on the U.S. Preventive Services Task Force (USPSTF) before it became notorious-back when "we felt like we were toiling in obscurity." Created by the Department of Health and Human Services (HHS) 3 decades ago, the panel examines clinical data and decides whether methods of preventing diseasemany of them already in use - are backed by evidence that they're worth using. Moyer's USPSTF term began in 2003 and except for a 2-year break, she has served ever since, becoming its chair in 2011. It was in 2009 that she and the rest of the task force shed their relative anonymity when they addressed a question many had thought settled: Should healthy women in their 40s get an annual mammogram?

The panel's explosive answer: No, because giving such advice would do more harm than good. It would lead to a huge number of false alarms and biopsies, the 16-member task force found, but would do little to reduce cancer deaths.

That's not how the panel worded its conclusion, however. Using carefully honed metrics, it gave a "C" grade (meaning weak) to evidence for benefits of mammography in this age group, a topic the task force had studied in various ways for years. After failing to agree on a first vote, USPSTF had commissioned new modeling studies to
Questioner. Pediatrician Virginia Moyer likes to ask, "Why are we doing this?"

clarify risks and benefits. Then the majority voted "against" a proposed recommendation that 40-year-olds get annual mammograms.

Turmoil ensued. Congressional committees grilled USPSTF members - nearly all of whom were physicians or nurses, and many of whom had Ph.D.s. Critics hastened to point out that none were cancer specialists. Advocates of mammography com-

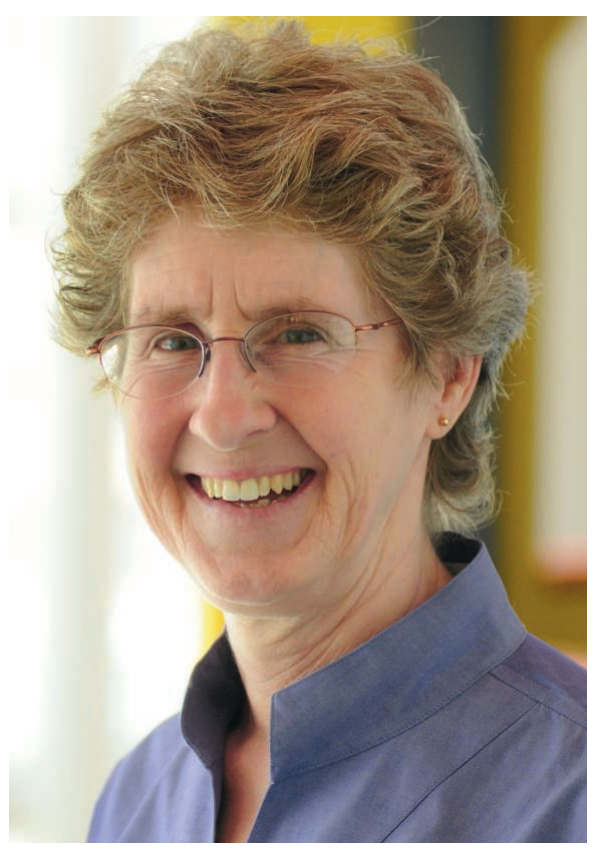

plained that a nerdy committee was trying to cut medical benefits. Radiologists claimed that, maybe because panel members didn't work directly with cancer patients, they undervalued the lifesaving power of mammography. Kathleen Sebelius, the HHS secretary, went on television to urge calm, arguably undercutting the panel by asking women to "do what you've always done: ... Talk to your doctor" (Science, 19 February 2010, p. 936).

The noisy response was partly the result of bad timing, says Moyer, a professor at Baylor College of Medicine in Houston, Texas. The task force issued its finding in the fall of 2009 when debate over the Administration's health care reform was raging and congressional election campaigns were heating up. It was a "perfect storm," agrees epidemiologist J. Michael McGinnis, an advocate of preventive health care and senior scholar at the Institute of Medicine in Washington, D.C.

USPSTF touched off another furor in May 2012 when it voted to reject a widely used method of screening for prostate cancer: the blood test based on prostate-specific antigen (PSA). In this case, USPSTF found strong negative evidence and concluded that routine screening of healthy men should stop. Urologists were outraged; since then, their professional associations have urged Congress to overhaul USPSTF. They want medical specialists like themselves seated on future USPSTF panels.

McGinnis says he expected some storms both within and outside government when, as a top HHS official, he created USPSTF in 1984. That's why HHS set it up as an independent body: "We wanted them to be totally unfettered by anything but the evidence in the way they went about their business." But the nature of controversy has

\title{
Public Health Measures in Disease Prevention
}

Vaccines for infectious pathogens, often mandatory, are a widespread method of preventing diseases in a population, but organizations and countries have also tackled noncommunicable diseases with a variety of public health measures. Here are some notable examples.

\footnotetext{
C-ING OFF SCURVY: results from a deficiency of vitamin $\mathrm{C}$ and prevents the formation of collagen. Scurvy was once a common problem for those on long marine voyages, killing more than a million sailors according to some estimates, but evidence slowly built that eating citrus fruits and other foods rich in vitamin C could prevent it. Ultimately, Britain's 1867 Merchant Shipping Act would mandate that sailors in the country's Royal Navy or Merchant Navy receive a daily ration of lime or lemon juice to prevent the condition.
}

PASS THE SALT: The mineral iodine plays a crucial role in the development of the body and the brain; a deficiency can lead to mental retardation, cretinism, and thyroid problems. Switzerland was the first to introduce iodized salt, in 1922, as a way to help prevent these conditions, and the United States and many other countries would soon adopt the practice.

 
changed since the 1980s. When USPSTF began, McGinnis says, he imagined that it would highlight the benefits of preventive services, "to show that the evidence base for prevention was even stronger than for many treatment interventions." At the time, clinical medicine "was overwhelmingly focused on the treatment side," McGinnis says.

McGinnis, who started in the Carter Administration and also served under presidents Ronald Reagan and Bill Clinton, agrees with Moyer that the 2009 storm over mammography was partly about politics. But he says that experts were at odds, and that unlucky timing and "poor communication" of findings contributed to USPSTF's woes.

Ned Calonge, the physician-epidemiologist who was chair of USPSTF when it made its mammography recommendations in 2009, says that what really surprised him was being shut out of the subsequent public debate. "It was frustrating to me not being able to counteract the very carefully crafted misinformation from the advocates" of mammography screening, says Calonge, now CEO of The Colorado Trust in Denver, a philanthropy. "We could not get control of the message."

In its early days, USPSTF undertook two reviews of more than 150 preventive measures - trying to cover the universe, McGinnis says. But medicine was changing too rapidly to keep up this pace; in the late 1990s the panel switched to doing analyses of single topics, which it now selects with input from researchers and the public. This year, for example, more than 20 topics are under review, from screening for abdominal aortic aneurysms to the use of vitamin D supplements to prevent cancer and osteoporosis.

Calonge, Moyer, and McGinnis all say that USPSTF needs to learn to communi- cate findings more clearly. And they agree on another point: A bill proposed in Congress this year to revamp USPSTF would not be a great way to improve scientific reviews. Introduced by Representative Marsha Blackburn (R-TN) and others, the USPSTF Transparency and Accountability Act of 2012 (H.R. 5998) would require the task force to include "stakeholders" and "specialty care providers" on decision-making panels. This is the plan backed by urological associations.

Moyer acknowledges that the task force can use advice from medical specialists, but only if they are experienced in clinical epidemiology and primary care - and are thoroughly impartial. Recruiting advocates as reviewers would defeat the purpose of the task force, she says.

Time is running out for the Blackburn bill in this Congress. But if it fails this year, the appeal to shake up USPSTF by including advocates may come back in 2013. Science recently spoke with Moyer about her role, her task force's recent fame, and its future. Her answers have been edited for brevity and clarity.

\section{-ELIOT MARSHALL}

\section{Q: How did you get into this field?}

V.M.: I think I got into evidence-based medicine because I tend to say, why are we doing this? (I have a journalist father and a scientist mother.) I was extremely fortunate to go to an early workshop sponsored by McMaster University, one of the birthplaces of evidence-based medicine. I got very involved. ... I had written a paper about whether there was any evidence for what we do in pediatric checkups. I looked at procedures that were recommended by at least two august bodies for these checkups and dug up the evidence for them, and it turns out there's not a lot of it. That doesn't mean they don't work.

\section{$0:$ On the task force, was there concern about potential harms from preventive measures from the beginning?}

V.M.: Yes, this was a new way of looking at things. We don't just say, "Oh, prevention is wonderful." As in all of medicine, you have to look at the upsides and the downsides, the benefits and the harms. ... If you have someone who feels fine when they come into the office, and you give them a screening test, you can't make them feel better. The only thing you can do is make them feel worse. So we balance both the benefits and the harms of any preventive service.

\section{Q: Did a concern over cost drive this balancing act?}

V.M.: That was not a big concern. It was more general. ... You don't want to do something that doesn't work - that is just a waste of money. More important, it is a waste of time. In a clinical encounter, you don't want to waste any of the limited time you have.

\section{0 : Why was the recommendation against routine mammography controversial?}

V.M.: The timing of the release coincided with health reform and the election. People were looking for a reason to be upset. ... The health care reform bill said that if the USPSTF makes a recommendation with a grade of A or B, that service would be firstdollar covered [by health care providers]. Well, the task force didn't give mammography for women aged 40 to 49 an A or B, so people interpreted it to mean they wouldn't be able to get [insurance] coverage. But that isn't what the recommendation says at all.

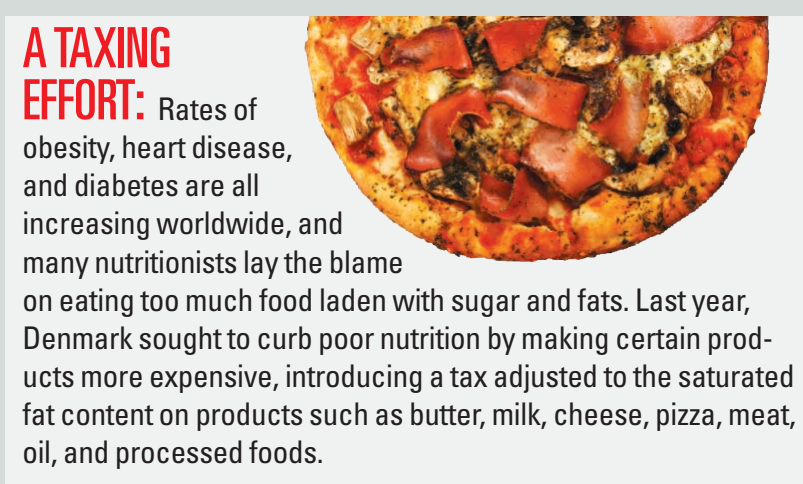

\begin{abstract}
THWARTING DECAY: Cavities, or caries, result when an infection - usually bacterialdemineralizes teeth, but more than a century ago researchers began to explore whether fluoride in water could stymie that process. After a study in a Michigan city showed that fluoridating the water supply reduced tooth decay among residents, U.S. officials backed the prevention strategy in 1951. Water fluoridation would soon become widespread in the United States and many other countries, though some worry about its other health implications or argue it infringes their rights.
\end{abstract}

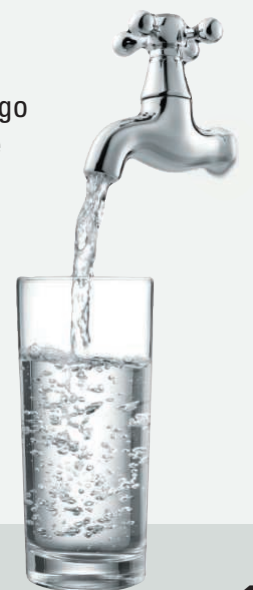




\section{0 : What did you take away from that experience?}

V.M.: We learned that we were suddenly in the public eye, which has dramatically changed how we communicate. We have expanded the transparency of what we do and opportunities for input from the public and from other stakeholders.

\section{0: Did you have public comment before? \\ V.M.: We did not. ..}

Everything went out for review to all kinds of people who we thought would be interested. Now it is put out on our Web site for anyone who wants to respond. We now invite public comment at the point when we are starting to think about a topic, so the public can say, "Well, you are not asking the right questions." ... It really helps us to understand what people are interested in, what they are concerned about.

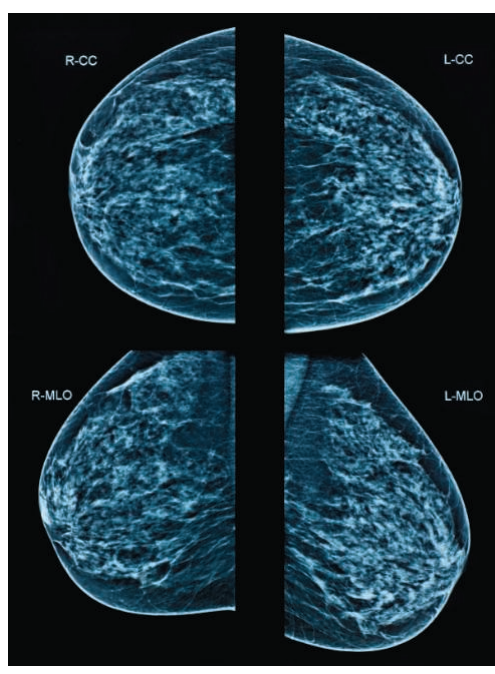

Screening shocker. The task force's decision on mammography upset many groups. hope [that preventive screening will work] and it is pretty painful to have that hope taken away.

\section{Q: Have task force recommendations caused a change in behavior?}

V.M.: There has been a change in mammography frequency - that has been pretty well studied now over the last couple of years.

And other experts may look at an issue and say, "I think you should frame it differently."

\section{0: Did the PSA recommendation turn out to be as controversial as mammography?}

V.M.: In some ways it is probably more controversial. The mammography recommendation itself is not all that exciting. ... It says: Think carefully because there are some downsides. ... Don't just leap into it. The PSA recommendation says: Don't do it. That has been very controversial with the urologists and with some but not all advocacy organizations. ... We all have great
And there have been a couple of studies looking at the frequency of PSA [tests]. And [both] have gone down a little bit.

\section{Q: Does it take a long time for recommenda- tions to be acknow- ledged?}

V.M.: Absolutely. We shouldn't be surprised by this. There are tons and tons of data out there on how long it takes for changes in health care to really take hold in practice. There was a study decades ago that's always quoted that says it takes 18 years to get anything new into practicethat may not be exactly accurate, but it is true that change is hard and it takes a long time.

\section{Q: There's a bill in Congress mandating that medical specialists be included on USPSTF panels. What do you think of it?} V.M.: It is important to recognize that ... we [at USPSTF] already do have the appropriate specialists on the panel: specialists in primary care and in evaluating science. Our recommendations are addressed to primary care clinicians about people who visit their generalists without specific concerns; these are not people who are going to specialists with a concern. If you put advocates on the panel, all you're doing is asking for advocacy, not science.

\section{Q: How much should task force work be linked to policy, such as spending decisions?}

V.M.: In many countries-England is a good example - the body that does the type of work we do is directly linked to policy decisions. In this country, that doesn't go as well. ... We do not do cost-effectiveness analysis. That is a scientific field in and of itself, and it's very resource-intensive. We don't do that.

\section{0: Some say it would be a mistake to link the scientific review and policy decisions because the science would suffer.}

V.M.: That tends to be right. ... We don't ignore the fact that there are [financial] costs associated with things, and we particularly consider cost to the individual to be a potential harm, but not in an explicit quantitative way. We do consider the fact that a false-positive test not only ends up requiring in many instances invasive and unpleasant procedures to determine that it was a false positive, but it can also be costly to the individual in time and money. My most recent false-positive mammogram cost me $\$ 2000$ out of pocket, because insurance only covers the mammogram; it doesn't cover the biopsy. Two thousand dollars is real money. Our purpose is not to save the system money. Our purpose is to improve the health of all Americans.

\section{Q: Will the task force always be in the middle of controversy?}

V.M.: Probably. And that's OK. Somebody needs to be looking at the things that we [physicians] always do with a critical eye.

\section{BABY SAFEGUARD: There's frequently}

debate about whether a screening method saves lives, but few doubt the effectiveness of one widely used method: the phenylketonuria (PKU) test now given to newborns in many industrialized countries. Often part of an arsenal of other newborn assays, the PKU test checks whether an infant has a toxic buildup of the amino acid phenylalanine, which can lead to mental retardation and other medical problems. If PKU is detected in a newborn, the infant can be given a specialized diet and avoid most health effects.

\section{TOBACCO WARNING: In response} to a 1964 report on smoking by the Surgeon General, the United States became the first country to mandate health-hazard warnings for cigarettes and other tobacco products. Other countries have followed suit, and the warnings have recently become even more graphic and aggressive.

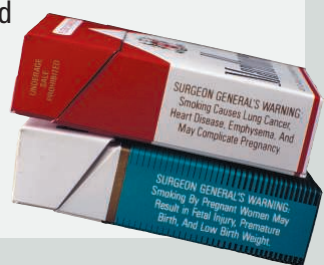

FLOUR POWER: breads, grains, flour, and other food products in many industrialized countries has been credited with reducing the number of babies born with neural tube defects. The U.S. Food and Drug Administration announced in 1996 that it would begin requiring folic acid fortification in certain foods, and a few other countries have taken the same action. Similarly, niacin has been voluntarily added to enriched flour in some countries to help ward off pellagra, the sometimes fatal disease caused by a B vitamin deficiency. 